\title{
Competition in pharmaceuticals: more product- than price-oriented?
}

\author{
Livio Garattini ${ }^{1} \cdot$ Anna Padula $^{1}$
}

Published online: 9 October 2017

(C) Springer-Verlag GmbH Germany 2017

\section{Introduction}

Competition is a subject always open to debate in health care, and pharmaceuticals are no exception, with the only clear difference from other 'markets' (e.g. hospital services) being that the supply side is private industry, worldwide.

Although the vast majority of pharmaceutical companies are multinationals nowadays and so many national differences have been smoothed, the presence of an important national pharmaceutical industry has historically affected the national policies of the major European countries [1]. For instance, the positive contribution to domestic economies (in terms of employment and trade export) favored a positive attitude towards the pharmaceutical industry in northern countries like Germany and the UK. In contrast, the chronic trade deficits in southern nations like Italy and Spain favored tighter pricing and reimbursement schemes, although even these were not necessarily effective in containing domestic expenses boosted by aggressive pharmaceutical marketing in these countries.

In general, the intrinsic limit of 'market failure' in health care [2] has steered a simplistic approach to competition in the pharmaceutical literature, mainly focused on price competition after patent expiry and with scant attention to product competition earlier.

Here, first, we summarize the theoretical concepts of price and product competition. Second, we analyze the main steps of pharmaceutical regulation during the 'life cycle' of a drug (patenting, registration, pricing and reimbursement),

Livio Garattini

livio.garattini@marionegri.it

1 IRCCS Institute for Pharmacological Research "Mario

Negri”, 24020 Ranica, Italy mainly referring to the European Union (EU). Third, we discuss whether and when some forms of price and/or product competition potentially play a role according to the present European regulation. Finally, we offer a comprehensive regulatory proposal to favor 'healthier' competition for 'merit goods' like drugs, from the patient's perspective rather than the general consumer's.

\section{Product and price competition}

The classic economic theory of perfect competition underlies a market in which products are fully homogeneous, consumers are price takers and there are no "entry or exit barriers' [3]. Competitors can only set different prices as a market strategy. Striving to maximize their profit, firms will sell a product as long as its marginal revenue is higher than the marginal cost. With the entry of new competitors, the price will slip down to the marginal cost in the long run, making this an ideal situation for consumers.

In early 1990s Hotelling introduced the more realistic, modern concept of product competition based on quality differentiation [4], which enables firms to compete beyond pricing in many markets. Competitors try to differentiate their products and compete more on quality than price in markets such as fashion, where product quality is highly valued by customers. To maximize profits, the best mix of product quality and price will mainly depend on the type of market. However, competitors need to differentiate their products to deter tough price competition and to be able to keep setting prices higher than marginal costs for a long period to maximize profits. 


\section{Pharmaceutical regulation}

\section{Patent protection}

Patents are by far the most exploited tool for protecting research and development (R\&D) investments in pharmaceuticals. Discoveries can flow into and depend on each other [5], with 'downstream' marketed drugs often generated by 'upstream' discoveries from publicly funded basic research. To prevent any form of plagiarism as soon as possible, pharmaceutical companies generally try to obtain the first patent very early. Later, the most effective means for extending a drug's patent protection is to obtain secondary patents by making series of modifications to the first invention [6]. Since the duration of market exclusivity is crucial for a pharmaceutical company to ensure economic returns before launching off-patent medicines [7], originator companies often follow 'evergreening' strategies to dramatically prolong patents [8].

Patents are still national in the EU, thus valid only in the countries where the patentee has applied for them. Patent claims can be filed through either the single national patent offices or the European Patent Office (EPO), the executive body created in 1977 to grant patents in different European countries at the same time for any kind of goods.

\section{Registration}

The registration process can last for years before drug market approval, implying a systematic review of the chemistry, pre-clinical pharmacology and toxicology data together with clinical trial (CT) data on drug safety and efficacy $[5,8]$. CTs are formally classified into four phases [9]. Phase I studies should investigate tolerability and dose titration, to establish whether a drug is safe. Phase II trials are mainly aimed at evaluating whether the drug has real biological activity, while phase III studies are designed to assess the efficacy and safety of the new drug in clinical practice. Later, phase IV trials should analyze the drug's long-term effects after market approval ('post-marketing surveillance').

Since 1995 the European Medicines Agency (EMA) has been the EU authority responsible for assessing the efficacy, safety and quality of medicines on the entire European market [10]. The latest EMA tendency is to fast-track drugs to marketing [11], so as to make new drugs available to patients as soon as possible. In practice, once preliminary efficacy and safety have been assessed, evaluations of comparative efficacy and cost-effectiveness are devolved to national authorities.

\section{Pricing}

Price schemes have historically been a policy response to control pharmaceutical expenditure [12]. A first apparently logical approach for price setting is to base it on estimates of the major cost items borne by industry (e.g. R\&D, manufacturing, marketing) [13]. Originally adopted in southern countries such as Italy and Spain, nowadays this type of scheme has been almost abandoned in the EU, mainly because of the difficulty of estimating single cost items per product in research-oriented multinational industries like today's pharmaceutical firms.

Secondly, a reference-based pricing approach can be applied to products considered therapeutically overlapping and thus competing with each other in the same 'market arena'. Originally introduced in Germany [14] and later adopted in the Netherlands, this approach is now applied in various forms (e.g., domestic and external reference prices) in many EU countries.

A third potential approach for price setting is to assess the perceived value of the product to customers by estimating their willingness to pay [15]. A similar scheme based on economic evaluation was announced by the previous UK government, but it no longer appears in the political agenda of the present one.

\section{Reimbursement}

Drugs are usually included in positive lists for reimbursement (e.g., national formularies in France and Italy), while in countries where reimbursement is implicitly granted after market approval (e.g., Germany and the UK) products with very limited efficacy can be grouped in a negative list later. In the EU countries where positive lists have been adopted (the majority), domestic authorities tend to run reimbursement procedures in parallel with pricing procedures (or even coinciding with them). In general, reimbursement decisions have to be supported by clinical evidence of efficacy and an economic evaluation for costeffectiveness, both included in the 'umbrella concept' of health technology assessment (HTA) [16].

At present, financial negotiations to reimburse expensive new drugs have become a common feature in most EU countries [13]. Many national authorities increasingly resort to price caps, confidential discounts, ceilings and paybacks by industry for cost containment. These negotiation strategies for reimbursement have somehow hidden (directly or indirectly) the real prices reimbursed for many drugs in various Western EU countries. Italy is a fine example, where the major concerns are burdensome administration and lack of transparency. 


\section{Patent expiry}

After patent expiry any manufacturer can by definition copy the originator product. This justifies the place in the market of off-patent medicines, drugs that are very likely to be sold at much lower prices than the originators since their manufacturing and marketing approval normally requires very limited investments [17]. Although it is easy enough to demonstrate bio-equivalence with originators, an important question arising from time to time on generics is the patient's perception of their quality, which tends to be erroneously associated with 'hard discount' low-quality products in mass markets; often there is also the interested support of pharmaceutical companies to undermine their credibility.

Many policies have been in place for decades to promote the use of generics in Western EU countries and specific price schemes have been adopted to encourage their wider use and thus constrain pharmaceutical expenditure [17]. Some countries (e.g., Germany and the Netherlands) have even extended competitive tenders on off-patent drugs from hospital services to community care.

\section{Critical issues}

Starting from patenting strategies, the pharmaceutical industry (by definition profit-oriented like any other private industry) strives to differentiate drugs, so as to maximize the return on R\&D expenditure during the global period of monopoly rent and hamper price competition even when drugs with overlapping efficacy are already on the market. Differently from the subsequent specific regulation on pharmaceuticals (inspired by drugs as 'merit goods' for health), patent regulation is part of commercial law and so lies outside public legislation. Accordingly, the EPO is a big general organization entirely funded by patent fees [18] and totally 'out of control' from the public health viewpoint, as well as the old national patent offices.

Differently, the EMA is a public EU agency specialized in managing drug market approvals. However, its present strategy of limiting companies' obligations for registering new drugs mainly to less risky CTs (superiority versus placebo and/or non-inferiority versus active comparators) [19] and then to postpone the appraisal of relative efficacy after marketing approval seems to favor extreme product differentiation as well.

As a consequence, national pricing and reimbursement strategies increasingly suffer the lack of clinical evidence [20] based on robust CTs (typically in the field of anticancer drugs). Although national authorities strive to exploit their purchasing power at most during negotiations, the present trend has made pricing and reimbursement puzzling and fragmented at domestic level in the EU [13], eventually jeopardizing reference price schemes which group drugs with similar efficacy under a common price regardless of patent protection [21].

After patent expiry national authorities can finally exploit price competition to the full, by imposing price cuts for reimbursed drugs and conducting competitive tenders. The originator prices can often be more than halved thanks to generics [17], since manufacturing costs hardly account for any substantial proportion of their prices. However, the growing number of complex biological agents may end up undermining tough price competition for these drugs after patent expiry, since their off-patent versions (biosimilars) will still require costly (and ethically questionable) CTs for market approval, the complicated biological production process of the originators being arguably kept secret [7].

\section{Alternative scenario}

An alternative approach to favor a more balanced mix of product and price competition in the EU and thus improve the long-term sustainability of public pharmaceutical expenditure (given ever increasing pressure on resources) would imply a substantial change of regulation, starting from patenting.

The EU could establish a specific agency dedicated to 'merit goods' for health (pharmaceuticals included) [22]. Although patents are traditionally part of commercial law, a specific approach for pharmaceuticals inspired by public health could be allowable in the present era of 'shareholder value' that drives up the share prices of big publicly traded pharmaceutical companies $[5,8]$. The excess of discretion by the pharmaceutical industry in filing patents and the consequent 'invention cascade' for secondary patents on the same drug seems hardly sustainable in the long run and often generates much costly litigation, which can be ultimately considered a waste of public money, as that is eventually funded by third payers in health care [22]. Primary patents on drugs could be restricted to compounds for one (or more) declared indication(s) and secondary patents should be granted only to very different indications later. Disclosure of the production process before patent expiry could lead to easier and more exact copying of the originator. More in general, EU authorities should hinder the widespread habit of big pharmaceutical companies to introduce in-patent pharmaceutical forms just before patent expiry [22], a 'malpractice' allowed by the present patent regulation to undermine price competition by extending protection through deliberately delayed launches.

In contrast to the current trend, an alternative EU pharmaceutical policy would also imply strengthening the EMA's role and expanding its tasks [19]. EMA should require industry to conduct 'head-to-head' CTs, in order to assess 
at the outset the therapeutic 'added value' of new drugs compared to best existing therapies. The evidence on relative efficacy would enable EMA to classify the new drugs approved according to their innovation potential and group them in at least two categories [13]: (1) drugs offering limited therapeutic gains, and (2) innovative drugs addressing important 'unmet needs'. Then national authorities could price the new drugs listed in the first group referring to the actual prices of their 'competitors' in domestic markets. The second group, presumably fairly small, could be subject to a value-based approach for pricing adapted at national level, taking account of the overall drug budget impact according to the local epidemiology.

For national reimbursement, this strategy should help limit arguable HTA exercises mainly based on long-term economic models populated by doubtful assumptions [23]. It also should prevent the spread of confidential discounts, a practice tolerated (if not backed) by industry to undermine international reference pricing. It is usually hard to assess which country and party these agreements are really benefiting. Moreover, the savings generated do not necessarily mirror the different purchasing power of third payers and in fact are more likely to raise inequalities among member States.

\section{Comment}

The present pharmaceutical regulation in the EU seems to privilege product rather than price competition, starting from the onset of a product's 'life cycle' until patent expiry. This type of market competition seems perfectly understandable from the supply side, with an R\&D-oriented industry like pharmaceuticals expecting high returns on investments, but it casts doubts on how health authorities - on the demand side - play their role of 'perfect agents' on behalf of citizens. This role does not prevent them from better exploiting their monopsonistic and oligopsonistic purchasing power in, respectively, Beveridgian and Bismarckian healthcare systems for pharmaceuticals. Here we put forward a proposal open to debate.

\section{References}

1. Garattini, L., Cornago, D., De Compadri, P.: Pricing and reimbursement of in-patent drugs in seven European countries: a comparative analysis. Health Policy 82(3), 330-339 (2007)

2. Bennett, S., Quick, J.D., Velásquez, G.: Public-private roles in the pharmaceutical sector: implications for equitable access and rational drug use. WHO/DAP/97.12. World Health Organization, Geneva (1997)

3. Machovec, F.M.: Perfect competition and the transformation of economics. Routledge, London (1995)

4. Cheng, Y.L., Peng, S.K.: Price competition and quality differentiation with multiproduct firms. J. Econ. 112(3), 207-223 (2014)

5. Mintzberg, H.: Patent nonsense: evidence tells of an industry out of social control. CMAJ 175(4), 374-381 (2006)

6. Spilker, B.: Guide to drug development—a comprehensive review and assessment. Lippincott Williams \& Wilkins, Philadelphia (2009)

7. van de Vooren, K., Curto, A., Garattini, L.: Biosimilar versus generic drugs: same but different? Appl. Health Econ. Health Policy 13(2), 125-127 (2015)

8. Feldschreiber, P., Breckenridge, A.: After thalidomide-do we have the right balance between public health and intellectual property. Rev. Recent Clin. Trials 10(1), 15-18 (2015)

9. Friedman, L.M., Furberg, C.D., DeMets, D.L.: Fundamentals of clinical trials, 4th edn. Springer, New York (2010)

10. EMA. Annual Report 2015. http://www.ema.europa.eu/docs/en_ GB/document_library/Annual_report/2016/05/WC500206482. pdf. Accessed 21 Sept 2016

11. Eichler, H.G., Baird, L.G., Barker, R., Bloechl-Daum, B., BørlumKristensen, F., Brown, J., et al.: From adaptive licensing to adaptive pathways: delivering a flexible lifespan approach to bring new drugs to patients. Clin. Pharmacol. Ther. 97, 234-246 (2015)

12. Ecorys-Research and Consulting. Competitiveness of the EU market and industry for pharmaceuticals. European Commission 2009. Ecorys, Rotterdam (2009)

13. Garattini, L., Curto, A., Freemantle, N.: Pharmaceutical price schemes in Europe: time for a 'Continental' one? Pharmacoeconomics 34(5), 423-426 (2016)

14. Giuliani, G., Selke, G., Garattini, L.: The German experience in reference pricing. Health Policy 44(1), 73-85 (1998)

15. Porter, M.E.: What is value in health care? N. Engl. J. Med. 363(26), 2477-2481 (2010)

16. Garattini, L., Casadei, G.: Health technology assessment: for whom the bell tolls? Eur. J. Health Econ. 9(4), 311-312 (2008)

17. Godman, B., Shrank, W., Wettermark, B., et al.: Use of genericsa critical cost containment measure for all healthcare professionals in Europe? Pharmaceuticals 3(8), 2470-2494 (2010)

18. Gates, C.: Patenting the life sciences at the European patent office. Cold Spring Harb. Perspect. Med. 4(12), a020792 (2014)

19. Garattini, L., Curto, A.: European Medicines Agency: leave the UK but remain the same? J. R. Soc. Med. 109(9), 324-325 (2016)

20. Garattini, L., Curto, A., Padula, A., Freemantle, N.: Real-world evidence in economic evaluations: really realistic? J. R. Soc. Med. 109(11), 404-407 (2016)

21. Schneeweiss, S.: Reference drug programs: effectiveness and policy implications. Health Policy 81(1), 17-28 (2007)

22. Garattini, L., Padula, A.: Between pharmaceutical patents and European patients: is a compromise still possible? Expert Opin. Ther. Pat. (2017). doi:10.1080/13543776.2017.1350648

23. Garattini, L., Koleva, D., Casadei, G.: Modeling in pharmacoeconomic studies: funding sources and outcomes. Int. J. Technol. Assess. Health Care 26(3), 330-333 (2010) 